\title{
Umbilical cord ghrelin concentrations in small- and appropriate-for-gestational age newborn infants: relationship to anthropometric markers
}

\author{
E E Önal, P Cinaz, Y Atalay, C Türkyilmaz, A Bideci, A Aktürk, \\ N Okumuş, S Ünal, E Koç and E Ergenekon
}

Gazi University Medical School, 06510 Besevier, Ankara, Turkey

(Requests for offprints should be addressed to E E Önal; Email: esraonal@gazi.edu.tr)

\begin{abstract}
Ghrelin is a newly discovered orexigenic peptide originating from the stomach. Circulating ghrelin levels reflect acute and chronic energy balance in humans. However, it is not known whether ghrelin also plays a role in energy homeostasis during fetal life. Forty-one small-forgestational age (SGA) and 34 appropriate-for-gestational age (AGA) infants were studied in order to determine whether cord blood ghrelin concentrations were different in SGA infants compared with AGA infants and the relationship to anthropometric measurements at delivery. The cord blood ghrelin concentrations of SGA infants (means \pm S.E.M.; $15 \cdot 20 \pm 3.08 \mathrm{ng} / \mathrm{ml}$ ) were significantly
\end{abstract}

greater than of AGA infants $(2.19 \pm 0.24 \mathrm{ng} / \mathrm{ml})$ $(P<0 \cdot 0001)$. They were negatively correlated with the infants' birth weights $(r=-0 \cdot 481, P<0 \cdot 0001)$ and with body mass index values $(r=-0.363, P<0 \cdot 001)$. The higher ghrelin concentrations were found in female infants $(20 \cdot 42 \pm 4 \cdot 55 \mathrm{ng} / \mathrm{ml})$ than in males $(7 \cdot 05 \pm 2 \cdot 27 \mathrm{ng} / \mathrm{ml})$ in the SGA group $(P=0 \cdot 042)$. These data provide the first evidence that cord ghrelin levels of SGA infants are greater than those of AGA infants and it is suggested that ghrelin is also affected by nutritional status in the intrauterine period.

Journal of Endocrinology (2004) 180, 267-271

\section{Introduction}

Ghrelin, an acylated peptide recently isolated from rat stomach, is a natural ligand for growth hormone secretagogue receptors and has potent growth hormone (GH)releasing activity with a dose-dependent manner (Kojima et al. 1999). The concentration of ghrelin has been shown to increase with fasting and decrease following feeding in humans and rats (Ariyasu et al. 2001, Nakazato et al. 2001). Ghrelin has also been shown to stimulate appetite and to induce adiposity, in addition to its effects on $\mathrm{GH}$ secretion (Tschöp et al. 2000, Wren et al. 2000, 2002, Asakawa et al. 2001). These data suggest that ghrelin may be an important link between nutrition and growth. Ghrelin levels have been found to be elevated in patients with anorexia nervosa compared with those in healthy controls and it is suggested that plasma ghrelin levels reflect acute and chronic energy balance in humans (Ariyasu et al. 2001).

Ghrelin is secreted mainly by the stomach, but also by many other organs, including the pituitary and the placenta (Gualillo et al. 2001). The presence of significant ghrelin concentrations in human cord blood has been shown but there is no study evaluating cord blood ghrelin levels in intrauterine growth-restricted infants (Chanoine et al. 2002).
The aim of this study was to determine whether cord blood ghrelin concentrations are different in small-forgestational age (SGA) infants compared with appropriatefor-gestational age (AGA) infants and its relationship to anthropometric measurements at delivery.

\section{Materials and Methods}

Seventy-five newborn infants born at Gazi University Medical School Hospital, Ankara, Turkey were enrolled in the study. Infants whose birth weight was below the 10th percentile (SGA group, $n=41$ ) were consecutively included in the study and defined as SGA. The AGA group, selected at random, consisted of 34 infants whose birth weight was between the 10th and the 90th percentile on the intrauterine growth charts of Lubchenco et al. (1963). Because national intrauterine growth curves are not available, the curves described by Lubchenco et al. (1963) were used. Demographic features and anthropometric measurements of the infants were recorded. Weight was measured using an electronic scale (Terrallion, Chatou, Cedex, France), length $( \pm 0 \cdot 1 \mathrm{~cm})$ was measured using a body-length measurer by a pediatric nurse and body mass index $\left(\mathrm{BMI} ; \mathrm{kg} / \mathrm{m}^{2}\right)$ was calculated. 
Infants with any congenital malformation, those whose mothers had a history of any chronic illness such as diabetes, autoimmune diseases, toxoplasmosis, others, rubella, cytomegalovirus and herpes simplex virus infections, pregnancy-induced hypertension and pre-eclampsia, infants from multiple gestations and those whose mothers had smoked during pregnancy were also excluded from the study. None of the mothers were suffering from malnutrition. Informed consent was obtained and the study was approved by the local ethics committee.

\section{Ghrelin assay}

At delivery, the umbilical cord was clamped immediately after the delivery of the infant, and then blood was drawn from the umbilical vein. Blood samples, anticoagulated with EDTA and aprotinin, were kept on ice, centrifuged at $1800 \mathrm{~g}$ for $15 \mathrm{~min}$ at $4{ }^{\circ} \mathrm{C}$ and plasma samples were separated and stored at $-80{ }^{\circ} \mathrm{C}$ until assayed.

Ghrelin levels were measured by using a commercial enzyme-linked immunosorbent assay kit (Ghrelin Human EIA Kit, EK-031-30; Phoenix Pharmaceuticals, Inc., Belmont, CA, USA) and samples for quality control were included in each assay. The intra-assay coefficients of variation for the assay were $<5 \%$ over the sample concentration range.

\section{Statistical analysis}

The chi-square test was used for comparing nominal variables between groups and the Mann-Whitney $U$ test was used for numeric variables. Spearman bivariate correlation analysis was applied to calculate the correlation between cord blood ghrelin levels and the anthropometric measurements of the infants. All statistical calculations were performed by using SPSS $10 \cdot 0$ for Windows program. A $P$ value of $<0.05$ was considered statistically significant.

\section{Results}

Birth weight, length and BMI of the SGA infants were significantly lower than those of the AGA infants. Gestational age and male/female ratio were similar in both groups. The clinical features of the subjects are shown in Table 1.

Cord blood ghrelin concentrations in SGA infants (means \pm S.E.M.; $15 \cdot 20 \pm 3.08 \mathrm{ng} / \mathrm{ml}$ ) were significantly greater than in AGA infants $(2 \cdot 19 \pm 0 \cdot 24 \mathrm{ng} / \mathrm{ml})$ $(P<0 \cdot 0001)$ (Fig. 1). Cord blood ghrelin concentrations were conversely correlated with the infants' birth weight $(r=-0.481, \quad P<0.0001)$ and BMI $\quad(r=-0.363$, $P=0 \cdot 001)$. Although ghrelin levels were similar in both sexes in the AGA infants, ghrelin levels in female infants
Table 1 Clinical features of study infants. Values are means \pm S.D.

\begin{tabular}{|c|c|c|c|}
\hline & $\begin{array}{l}\text { SGA } \\
(n=41)\end{array}$ & $\begin{array}{l}\text { AGA } \\
(n=34)\end{array}$ & $P$ value \\
\hline Gestational age (weeks) & $38 \cdot 9 \pm 1 \cdot 2$ & $38 \cdot 9 \pm 1 \cdot 0$ & $0 \cdot 893$ \\
\hline Birth weight $(\mathrm{g})$ & $2315 \pm 264$ & $3131 \pm 303$ & $<0 \cdot 0001$ \\
\hline Birth length $(\mathrm{cm})$ & $45 \cdot 8 \pm 2 \cdot 1$ & $49 \cdot 6 \pm 1 \cdot 7$ & $<0 \cdot 0001$ \\
\hline BMI $\left(\mathrm{kg} / \mathrm{m}^{2}\right)$ & $11 \cdot 2 \pm 1 \cdot 2$ & $12 \cdot 8 \pm 0 \cdot 9$ & $<0 \cdot 0001$ \\
\hline Sex (female/male) & $25 / 16$ & $15 / 19$ & $0 \cdot 144$ \\
\hline Apgar score (5th min) & $9 \pm 1$ & $9 \pm 1$ & $1 \cdot 000$ \\
\hline $\begin{array}{l}\text { Delivery route (vaginal/ } \\
\text { Caesarean section) }\end{array}$ & $20 / 21$ & $16 / 18$ & $0 \cdot 882$ \\
\hline Mothers' age (years) & $25 \cdot 2 \pm 4 \cdot 7$ & $27 \cdot 1 \pm 5 \cdot 4$ & $0 \cdot 110$ \\
\hline
\end{tabular}

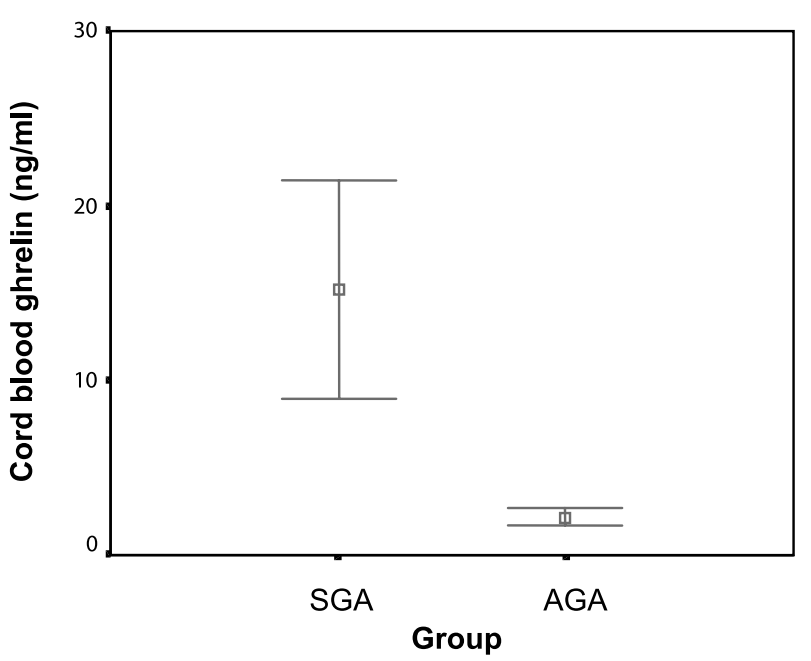

Figure 1 Mean ( \pm 2 S.E.M.) cord blood ghrelin concentrations in the SGA and the AGA infants $(P<0 \cdot 0001)$.

were greater than in male infants in the SGA group $(P=0.042) \quad$ (Fig. 2). Birth weights of female infants (means \pm S.D.; $2268 \pm 283 \mathrm{~g}$ ) were slightly lower than those of males $(2388 \pm 219 \mathrm{~g})$ in the SGA group $(P=0 \cdot 190)$. Ghrelin levels in the newborns born by vaginal delivery (means \pm S.E.M.; $17 \cdot 03 \pm 4.79 \mathrm{ng} / \mathrm{ml}$ ) were similar to those born by Caesarean section $(13.46 \pm 3.96 \mathrm{ng} / \mathrm{ml})$ in the SGA group $(P=0.804)$ and similar in the AGA group $(2 \cdot 31 \pm 0 \cdot 36 \mathrm{ng} / \mathrm{ml}$ for vaginal vs $2.09 \pm 0.34 \mathrm{ng} / \mathrm{ml}$ for Caesarean section $)(P=0.654)$.

\section{Discussion}

We have found that the cord blood concentrations of ghrelin in SGA infants were greater than those in AGA infants. Although ghrelin has been shown to increase in anorexia and decrease in obesity in humans and has been suggested to play a role in the regulation of energy homeostasis, the increased cord ghrelin concentrations in intrauterine growth-restricted infants compared with 


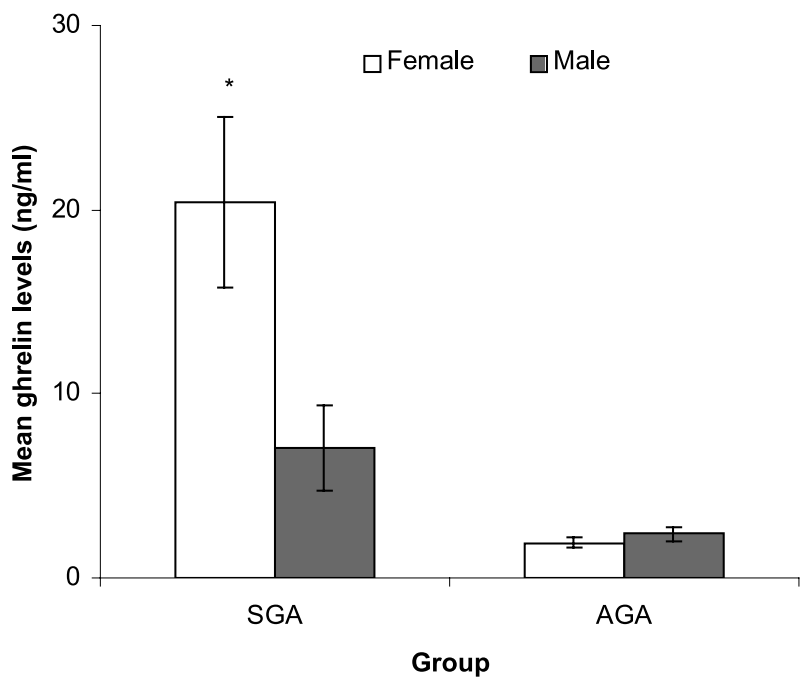

Figure 2 Cord blood ghrelin levels in female and male infants in the SGA and AGA groups $\left({ }^{*} P<0 \cdot 05\right)$. Data are means \pm S.E.M.

healthy newborns has not previously been reported (Ariyasu et al. 2001, Tschöp et al. 2001, Haqq et al. 2003).

Ghrelin has been implicated in both meal-time hunger and the long-term regulation of body weight. The increased levels of circulating ghrelin after weight loss is consistent with a role of ghrelin in the long-term regulation of body weight in humans (Ariyasu et al. 2001, Cummings et al. 2002, Hansen et al. 2002). In addition, continuous administration of ghrelin increases body weight and, besides increasing food intake, exogenous ghrelin decreases the metabolic rate and the catabolism of fat, thereby affecting all aspects of the system of energy regulation in such a way as to increase body weight (Tschöp et al. 2000, Nakazato et al. 2001). Although ghrelin mRNA transcription has been shown in the placenta in humans, its role in the intrauterine period is not clear. It has been shown that ghrelin administration to pregnant rats caused an increase in the body weight of newborn rats and ghrelin has been suggested to be involved in neonatal growth (Hayashida et al. 2002). Therefore, ghrelin may also have a role in energy regulation in fetal life.

Plasma ghrelin levels are found to be extremely high in patients with anorexia nervosa compared with after 12-h fasting in normal subjects, and the levels were negatively correlated with BMI. This observation raises the idea that ghrelin also reflects the chronic feeding state (Ariyasu et al. 2001). In other studies, plasma ghrelin concentrations have also been reported to be negatively correlated with BMI in humans (Shiiya et al. 2002, Haqq et al. 2003). Similarly, in our study, we also found that cord ghrelin concentrations correlated with birth weight and BMI which was consistent with the results of previous studies. Birth weight is suggested to be a marker of adiposity in newborns.
Additionally, body weight measurement is the easiest and the most reliable method among anthropometric measurements to indicate the nutritional status of newborns and birth weight is the most used marker indicating fetal neonatal growth. Although birth weight and BMI are indirect markers of adiposity, it has been shown that BMI and weight are correlated with total body fat as derived by total body electrical conductivity which is an accurate, precise and reproducible method for estimating total body fat in infants (deBruin et al. 1995). Therefore, we investigated the correlation between cord ghrelin levels and birth weight and BMI of infants as indirect markers of nutritional status. Moreover, markedly increased cord ghrelin concentrations in the SGA infants in the present study may be due to the state of undernutrition of those infants.

Infants in the SGA group in this study were assumed to be intrauterine growth restricted due to unknown etiologies, as infants who had congenital malformations and whose mothers had any condition known to be a cause of intrauterine growth restriction (IUGR) were excluded from the study. Makino et al. (2002) have reported a negative correlation between plasma ghrelin concentration and systemic blood pressure in normal pregnant women, and higher ghrelin levels in pregnant women with pregnancy-induced hypertension than normal pregnant women. On the other hand, Tschöp et al. (2001) have shown that fasting plasma ghrelin was negatively correlated with fasting insulin and Masaoka et al. (2003) have reported significantly increased plasma ghrelin levels in diabetic rats. Therefore, the possible effects of certain pathologic conditions on fetal ghrelin regulation are not clearly understood. As we excluded subjects whose mothers had various pathologic conditions perhaps causing IUGR, we could then omit the possible effects of those conditions on ghrelin levels.

We included SGA infants as a study group and assumed that they were intrauterine growth restricted. Although IUGR denotes a pathophysiologic process resulting in restriction of fetal growth, and SGA refers to a statistical grouping of infants below the 10th percentile, IUGR is often used synonymously with SGA. We did not diagnose IUGR clinically but we defined SGA infants according to their birth weight, which is a more objective criteria than physical findings consistent with IUGR diagnosis clinically. Nevertheless, there would, of course, be a distinction between the SGA and the IUGR classifications in extreme cases.

The neuroendocrine mechanism regulating GH secretion appears to be exquisitely sensitive and responsive to nutritional state in humans. Fasting stimulates $\mathrm{GH}$ release in humans and infants with IUGR who characteristically show elevated basal levels of GH (Leger et al. 1996, Cance-Rouzaud et al. 1998). It has been unclear, however, what factors specifically activate this system in undernutrition. Although we did not measure the $\mathrm{GH}$ 
levels, which is a weakness of this study, the results suggested that the augmented ghrelin levels might consequently lead to elevated GH levels as ghrelin has a potent GH-releasing activity.

Chanoine et al. (2002) showed the presence of immunoreactive ghrelin in cord samples of full-term newborns. They reported that ghrelin was inversely correlated with anthropometric measures and similar ghrelin concentrations were found in female and male infants. Similarly, the cord ghrelin levels were found to conversely correlate with birth weight in our study. Although the ghrelin levels of female infants were similar to those of male healthy newborns, greater values in female than in male infants were found in the SGA group in the present study, in contrast to the results of Chanoine et al. (2002). Similarly, there are some studies reporting higher leptin levels in female infants than in male infants (Helland et al. 1998, Lönnerdal \& Havel 2000), whereas some reports have suggested no gender difference in cord plasma leptin levels in infants (Schubring et al. 1997, Shekhawat et al. 1998). Additionally, there has been no study suggesting that ghrelin might be regulated by estrogen. Therefore this finding might be due to the lower birth weights of the female infants in this group.

We have shown that the cord ghrelin levels in infants born by vaginal delivery were not different from infants born by Caesarean section and concluded that delivery mode did not affect the cord ghrelin levels.

Cord ghrelin concentrations measured in this study seem to be higher compared with plasma ghrelin concentrations in children and adults in previous studies (Ariyasu et al. 2001, Bellone et al. 2002, Haqq et al. 2003). However, it is necessary to investigate whether ghrelin levels change with age. If plasma ghrelin levels decrease with age, then it will be consistent with decreasing $\mathrm{GH}$ levels with age in humans.

The origin of the increased levels of ghrelin in cord blood in the SGA infants is also important. Both fetal and placental ghrelin secretion has been demonstrated so the two sources would be expected. However, Gualillo et al. (2001) have shown that ghrelin mRNA in pregnant rats showed a characteristic profile of expression. We did not find any correlation between gestational age and cord ghrelin levels. Additionally, placental size is considered to be lower in SGA pregnancies than in AGA ones. Therefore, we hypothesize that cord ghrelin levels should be fetal in origin rather than placental. Nevertheless, we could not support this hypothesis with the results of this study. It is worthwhile investigating the origin of ghrelin in cord blood.

In summary, cord ghrelin concentrations in the SGA infants were significantly greater than those in the AGA infants, and they were negatively correlated with birth weight and BMI. These findings suggest that ghrelin is involved in energy homeostasis and is affected by nutritional status also in intrauterine life.

\section{References}

Ariyasu H, Takaya K, Tagami T, Ogawa Y, Hosoda K, Akamizu T, Suda M, Koh T, Natsui K, Toyooka S et al. 2001 Stomach is a major source of circulating ghrelin, and feeding state determines plasma ghrelin-like immunoreactivity levels in humans. Journal of Clinical Endocrinology and Metabolism 86 4753-4758.

Asakawa A, Inui A, Kaga T, Yuzuriha H, Nagata T, Ueno N, Makino S, Fujimiya M, Niijima A, Fujino MA et al. 2001 Ghrelin is an appetite-stimulatory signal from stomach with structural resemblance to motilin. Gastroenterology 120 337-345.

Bellone S, Rapa A, Vivenza D, Castellino N, Petri A, Bellone J, Me E, Broglio F, Ghigo E \& Bona G 2002 Circulating ghrelin levels as function of gender, pubertal status and adiposity in childhood. Journal of Endocrinological Investigation 25 RC13-RC15.

deBruin NC, van Velthoven KAM, Stijnen T, Juttmann RE, Degenhart HJ \& Visser HKA 1995 Body fat and fat-free mass in infants: new and classic anthropometric indexes and prediction equations compared with total-body electrical conductivity. American Journal of Clinical Nutrition 61 1195-1205.

Cance-Rouzaud A, Laborie S, Bieth E, Tricoire J, Rolland M, Grandjean H, Rochiccioli P \& Tauber M 1998 Growth hormone, insulin-like growth factor-I and insulin-like growth factor binding protein-3 are regulated differently in small-for-gestational-age and appropriate-for-gestational-age neonates. Biology of Neonate $\mathbf{7 3}$ 347-355.

Chanoine JP, Yeung LP, Wong AC \& Birmingham CL 2002 Immunoreactive ghrelin in human cord blood: relation to anthropometry, leptin, and growth hormone. Journal of Pediatric Gastroenterology and Nutrition 35 282-286.

Cummings DE, Weigle DS, Frayo RS, Breen PA, Ma MK, Dellinger EP \& Purnell JQ 2002 Plasma ghrelin levels after diet-induced weight loss or gastric bypass surgery. New England Journal of Medicine 346 1623-1630.

Gualillo O, Caminos J, Blanco M, Garcia-Caballero T, Kojima M, Kangawa K, Dieguez C \& Casanueva F 2001 Ghrelin, a novel placental-derived hormone. Endocrinology 142 788-794.

Hansen TK, Dall R, Hosoda H, Kojima M, Kangawa K, Christiansen JS \& Jorgensen JO 2002 Weight loss increases circulating levels of ghrelin in human obesity. Clinical Endocrinology 56 203-206.

Haqq AM, Farooqi IS, O'Rahilly S, Stadler DD, Rosenfeld RG, Pratt KL, LaFranchi SH \& Purnell JQ 2003 Serum ghrelin levels are inversely correlated with body mass index, age, and insulin concentrations in normal children and are markedly increased in Prader-Willi syndrome. Journal of Clinical Endocrinology and Metabolism 88 174-178.

Hayashida T, Nakahara K, Mondal MS, Date Y, Nakazato M, Kojima M, Kangawa K \& Murakami N 2002 Ghrelin in neonatal rats: distribution in stomach and its possible role. Journal of Endocrinology 173 239-245.

Helland IB, Reseland JE, Saugstad OD \& Drevon CA 1998 Leptin levels in pregnant women and newborn infants: gender differences and reduction during the neonatal period. Pediatrics 101 E12.

Kojima M, Hosada H, Date Y, Nakazato M, Matsui H \& Kangawa K 1999 Ghrelin is a growth-hormone releasing acylated peptide from stomach. Nature 402 656-660.

Leger J, Noel M, Limal JM \& Czernichow P 1996 Growth factors and intrauterine growth retardation. II. Serum growth hormone, insulin-like growth factor (IGF)I, and IGF-binding protein 3 levels in children with intrauterine growth retardation compared with normal control subjects: prospective study from birth to two years of age. Study Group of IUGR. Pediatric Research 40 101-107.

Lönnerdal B \& Havel PJ 2000 Serum leptin concentrations in infants: effects of diet, sex, and adiposity. American Journal of Clinical Nutrition 72 484-489.

Lubchenco LO, Hansman C \& Boyd E 1963 Intrauterine growth as estimated from live born birth-weight data at 24-42 weeks of gestation. Pediatrics 32 793-798. 
Makino Y, Hosoda H, Shibata K, Makino I, Kojima M, Kangawa K \& Kawarabayashi T 2002 Alteration of plasma ghrelin levels associated with the blood pressure in pregnancy. Hypertension 39 781-784.

Masaoka T, Suzuki H, Hosoda H, Ota T, Minegishi Y, Nagata H, Kangawa K \& Ishii H 2003 Enhanced plasma ghrelin levels in rats with streptozotocin-induced diabetes. FEBS Letters 541 64-68.

Nakazato M, Murakami N, Date Y, Kojima M, Matsuo H, Kangawa K \& Matsukura S 2001 A role for ghrelin in the central regulation of feeding. Nature 409 194-198.

Schubring C, Kiess W, Englaro P, Rascher W, Dotsch J, Hanitsch S, Attanasio A \& Blum WF 1997 Levels of leptin in maternal serum, amniotic fluid, and arterial and venous cord blood: relation to neonatal and placental weight. Journal of Clinical Endocrinology and Metabolism 82 1480-1483.

Shekhawat PS, Garland JS, Shivpuri C, Mick GJ, Sasidharan P, Pelz CJ \& McCormick KL 1998 Neonatal cord blood leptin: its relationship to birth weight, body mass index, maternal diabetes, and steroids. Pediatric Research 43 338-343.

Shiiya T, Nakazato M, Mizuta M, Date Y, Mondal MS, Tanaka M, Nozoe SI, Hosoda H, Kangawa K \& Matsukura S 2002 Plasma ghrelin levels in lean and obese humans and the effect of glucose on ghrelin secretion. Journal of Clinical Endocrinology and Metabolism 87 240-244.

Tschöp M, Smiley DL \& Heiman ML 2000 Ghrelin induces adiposity in rodents. Nature 47 908-913.

Tschöp M, Weyer C, Tataranni PA, Devanarayan V, Ravussin E \& Heiman ML 2001 Circulating ghrelin levels are decreased in human obesity. Diabetes $\mathbf{5 0}$ 707-709.

Wren AM, Small CJ, Ward HL, Murphy KG, Dakin CL, Taheri S, Kennedy AR, Roberts GH, Morgan DGA, Ghatei MA et al. 2000 The novel hypothalamic peptide ghrelin stimulates food intake and growth hormone secretion. Endocrinology 141 4325-4328.

Wren AM, Seal LJ, Cohen MA, Brynes AE, Frost GS, Murphy KG, Dhillo WS, Ghatei MA \& Bloom SR 2002 Ghrelin enhances appetite and increases food intake in humans. Journal of Clinical Endocrinology and Metabolism 86 5992-5997.

Received in final form 23 September 2003 Accepted 3 October 2003 